\title{
Effects of Music on Physiological Arousal: Explorations into Tempo and Genre
}

\author{
FRANCESCA R. DILLMAN CARPENTIER \\ University of North Carolina at Chapel Hill \\ ROBERT F. POTTER \\ Indiana University
}

\begin{abstract}
Two experiments explore the validity of conceptualizing musical beats as auditory structural features and the potential for increases in tempo to lead to greater sympathetic arousal, measured using skin conductance. In the first experiment, fast-and slow-paced rock and classical music excerpts were compared to silence. As expected, skin conductance response (SCR) frequency was greater during music processing than during silence. Skin conductance level (SCL) data showed that fast-paced music elicits greater activation than slow-paced music. Genre significantly interacted with tempo in SCR frequency, with faster tempo increasing activation for classical music and decreasing it for rock music. A second experiment was conducted to explore the possibility that the presumed familiarity of the genre led to this interaction. Although further evidence was found for conceptualizing musical beat onsets as auditory structure, the familiarity explanation was not supported.
\end{abstract}

Music communicates many different types of messages through the combination of sound and lyrics (Sellnow \& Sellnow, 2001). For example, music can be used to exchange political information (e.g., Frith, 1981; Stewart, Smith, \& Denton, 1989). Music can also establish and portray a self- or groupimage (Arnett, 1991, 1992; Dehyle, 1998; Dillman Carpentier, Knobloch \& Zillmann, 2003; Kendall \& Carterette, 1990; Manuel, 1991; McLeod, 1999; see also Hansen \& Hansen, 2000). Pertinent to this investigation, music can communicate emotional information (e.g., Juslin \& Sloboda, 2001). In short,

The authors contributed equally to this manuscript and are listed alphabetically.

Address correspondence to Francesca R. Dillman Carpentier, School of Journalism \& Mass Communication, University of North Carolina at Chapel Hill, CB\# 3365, Chapel Hill, NC 27599. E-mail: francesca@unc.edu 
music is a form of "interhuman communication in which humanly organized, non-verbal sound is perceived as vehiculating primarily affective (emotional) and/or gestural (corporeal) patterns of cognition" (Tagg, 2002, p. 5).

This idea of music as communication reaches the likes of audio production students, who are taught the concept of musical underscoring, or adding music to "enhance information or emotional content" in a wide variety of ways from establishing a specific locale to intensifying action (Alten, 2005, p. 360). In this realm, music becomes a key instrument in augmenting or punctuating a given message. Given the importance of arousal and/or activation in most theories of persuasion and information processing, an understanding of how music can be harnessed to instill arousal is arguably of benefit to media producers looking to utilize every possible tool when creating messages, whether the messages are commercial appeals, promotional announcements or disease-prevention messages. It is with the motivation of harnessing the psychological response to music for practical application that two experiments were conducted to test whether message creators can rely on musical tempo as a way to increase sympathetic nervous system activation in a manner similar to other structural features of media (i.e., cuts, edits, sound effects, voice changes). Before explaining the original work, a brief description of the current state of the literature on music and emotion is offered.

\section{Different Approaches in Music Psychology}

Although there is little doubt that music "vehiculates" emotion, several debates exist within the music psychology literature about exactly how that process is best conceptualized and empirically approached (e.g., Bever, 1988; Gaver \& Mandler, 1987; Juslin \& Sloboda, 2001; Lundin, 1985; Sloboda, 1991). The primary conceptual issue revolves around two different schools of thought (Scherer \& Zentner, 2001). The first, the cognitivist approach, describes emotional response to music as resulting from the listener's cognitive recognition of cues within the composition itself. Emotivists, on the other hand, eliminate the cognitive calculus required by cue recognition in the score, instead describing emotional response to music as a feeling of emotion. Although both approaches acknowledge a cultural or social influence in how the music is interpreted (e.g., Krumhansl, 1997; Peretz, 2001), the conceptual chasm between emotion as being either expressed or elicited by a piece of music is wide indeed.

A second issue in the area of music psychology concerns a difference in the empirical approach present among emotion scholars writ large. Some focus their explorations on specific, discrete affective states (i.e., joy, fear, disgust, etc.), often labeled as the experience of basic emotions (Ortony, Clore, \& Collins, 1988; Thayer, 1989; Zajonc, 1980). Communication scholars such as Nabi (1999, 2003) and Newhagen (1998) have also found it fruitful to explore unique affective states resulting from mediated messages, driven 
by the understanding that "each emotion expresses a different relational meaning that motivates the use of mental and/or physical resources in ways consistent with the emotion's action tendency" (Nabi, 2003, p. 226; also see Wirth \& Schramm, 2005 for a review). This approach is also well represented by studies exploring human reactions to music (see Juslin \& Laukka, 2003 for a review).

Other emotion scholars design studies where the focus is placed not on the discrete identifier assigned to a certain feeling-state by a listener, but rather the extent to which different feeling-states share common factors or dimensions. The two most commonly studied dimensions are valence-a term given to the relative positive/negative hedonic value, and arousal-the intensity or level to which that hedonic value is experienced. The centrality of these two dimensions in the published literature is due to the consistency with which they account for the largest amount of predictive variance across a wide variety of dependent variables (Bradley, 1994; Osgood, Suci, \& Tannenbuam, 1957; Reisenzein, 1994; Russell, 1980). This dimensional approach to emotional experience is well-represented by articles in the communication literature exploring the combined impact of valence and arousal on memory (Lang, Bolls, Potter, \& Kawahara, 1999; Sundar \& Kalyanaraman, 2004), liking (Yoon, Bolls, \& Lang, 1998), and persuasive appeal (Potter, LaTour, Braun-LaTour, \& Reichert, 2006; Yoon et al., 1998). When surveying the music psychology literature for studies utilizing the dimensional emotions approach, however, results show that the impact of music on hedonic valence are difficult to consistently predict-arguably due to contextual, experiential or mood-state influences of the listener combined with interpretational differences of the song composers and performers (Bigand, Filipic, \& Lalitte, 2005; Cantor \& Zillmann, 1973; Gabrielsson \& Lindström, 2001; Kendall \& Carterette, 1990; Leman, 2003; Lundin, 1985).

On the other hand, the measured effects of music on the arousal dimension, although not uniform, are more consistent across studies (see Juslin \& Sloboda, 2001). For example, numerous experiments have noted the relaxation potential of music - either using compositions pre-tested as relaxing or self-identified by research participants as such. In Bartlett's (1996) review of music studies using physiological measures, a majority of studies measuring muscle tension found relaxing music to reduce it. Interestingly, slightly more than half of the studies that measured skin temperature found relaxing music to increase it.

Pelletier (2004) went beyond reviewing studies individually, conducting a statistical meta-analysis of 22 experiments. Conclusions showed that music alone, as well as used in tandem with relaxation techniques, significantly decreased perceived arousal and physiological activation. However, the amount of decrease significantly varied by age, stressor, musical preference, and previous music experience of the participant. These caveats provide possible explanations for the few inconsistent findings across individual studies that 
show either little or no effects of relaxing music (e.g., Davis-Rollans \& Cunningham, 1987; Robb, Nichols, Rutan, Bishop, \& Parker, 1995; Strauser, 1997; see Standley, 1991 for review) or that show listening to relaxing music yields higher perceived arousal compared to the absence of music (Davis \& Thaut, 1989).

Burns, Labbé, Williams, and McCall (1999) relied on both self-report and physiological responses to the musical selections to explore music's ability to generate states of relaxation. The researchers used a predetermined classical excerpt, a predetermined rock excerpt, an excerpt from a "relaxing" selection chosen by each participant, and a condition of sitting in silence. Burns et al. (1999) found that, within groups, both finger temperature and skin conductance decreased over time. Across emotional conditions, selfreported relaxation was lowest for rock listeners and highest for participants in the self-selection and silence conditions. However, no significant betweengroup physiological differences were found.

Rickard (2004) also combined self-reports of emotional impact, enjoyment, and familiarity with psychophysiological measures in evaluating arousal effects of music. Psychophysiological measures included skin conductance responses, chills, skin temperature, and muscle tension. Stimuli included relaxing music, music predetermined to be arousing but not emotionally powerful, self-selected emotionally powerful music, and an emotionally powerful film scene. Rickard found that music participants had self-identified as emotionally powerful led to the greatest increases in skin conductance and chills, in addition to higher ratings on the self-reported measures. No correlation was found between these effects and participant gender or musical training.

Krumhansl (1997) explored how music affects the peripheral nervous system in eliciting emotions in college-aged music students. Classical music selections approximately 180-seconds long were chosen which expressed sadness, happiness, or fear. While listening, half of the participants made dynamic emotional judgments about how the music made them feel. Physiological data were collected during the listening session from the other half of participants. After each selection, all participants completed a questionnaire assessing feelings they had experienced during the piece. All music, regardless of which discrete emotion was represented, resulted in decreased heart rate and increased breathing rate and blood pressure. In addition, all excerpts led to an aggregated decrease in sympathetic system measures (i.e., skin conductance level and finger temperature). Such a decrease in physiological activation is expected because of increases in comfort, familiarity, and even boredom as experimental sessions proceed. Interestingly, however, there was also a main effect for discrete emotion in Krumhansl's data, with greater sympathetic activation found in happy excerpts, followed by fear and sadness. The statistical analysis of the dynamic nature of this effect over time was correlational—calculating separate Pearson $r$-values between time and, for example, skin conductance level. Not surprisingly, given the deceleratory 
nature of autonomic activation during an experimental session, results show greater negative correlations as the music progressed. Unfortunately, such an analysis leaves no real sense of the comparative dynamic nature of the impact of different music excerpts.

Several studies have attempted to tease out which aspects of music result in increased states of arousal in listeners. For example, studies testing the effects of tempo and mode (major or minor key) on self-reported perceived arousal and mood have found that, whereas mode typically affects mood, increased tempo leads to increased self-reported arousal (Holbrook \& Anand, 1990; Husain, Thompson, \& Schellenberg, 2002; Kellaris \& Kent, 1993; Schubert, 2004; see Lundin, 1985 for review). Kellaris and Kent (1993) had respondents listen to original compositions that varied by what they labeled tempo, tonality (major, minor, atonal) and texture (classical, pop). Respondents provided self-reported assessments of both the pleasure and arousal they obtained from the music. Results show faster tempos led to more reported arousal and pleasure, an effect that was moderated by the genre the music represented. Specifically, increases in tempo led to greater selfreported pleasure during classical music selections but greater arousal during pop music. Tonality was found to be unrelated to self-reported arousal.

\section{The Current Experiments}

The general goal of this research is to investigate whether tempo can be harnessed to increase activation of the autonomic nervous system and thereby elevate listener arousal. Stating the goals in such a way not only places these two experiments among those using an emotivist conceptualization, but also clearly investigates the question from a dimensional point of view. This choice of theoretical approach was deliberate, although not meant to discount the viability of discrete emotion theories and the likelihood that very specific emotional feeling-states play a role in attitude formation, persuasion, and even in program selection. Neither should the focus on tempo in this study imply a lack of awareness that other features identified in the music literature (melodic contour, pitch, tonality, etc.) go quite far in communicating discrete emotions (Gabrielsson \& Lindström, 2001). Instead, the interests of this study center on whether individual musical beats can be regarded in a similar manner to other auditory structural features that have been shown to cause greater sympathetic system activation when their pacing was increased.

For example, results from work done by Potter and his colleagues have shown that increasing the frequency of onset for certain auditory structural features-namely those that cause cardiac orienting responses and a resulting allocation of cognitive processing to message encoding (Potter, 2000; 2006; Potter, Lang, \& Bolls, 1998)—lead to increased self-reported and psychophysiological arousal (Potter \& Callison, 1999; Potter \& Choi, 2006; Potter, 
Choi, Yu, Kim, \& Dillman Carpentier, 2002). If data show that musical beats can be conceptualized in a similar manner, then increasing the tempo of musical underscoring could be recommended as a way to heighten arousal and the experience of intended discrete emotional states that message producers desire. Furthermore, if the resulting increase in arousal occurs, one might also expect stronger memory associations between that discrete emotion and the substance of the message content, be it a commercial sponsor, philanthropic cause, or movie title (Bolls, Lang, \& Potter, 2001; Potter \& Callison, 2000).

As mentioned above, Burns et al. (1999) found substantially larger increases in self-reported feelings of relaxation among participants in a silence condition compared to classical and rock music selections, consistent with a conceptualization of musical notes as auditory structure capable of eliciting sympathetic activation. In an attempt to extend their finding beyond self-reported data, the following hypothesis is made:

H1a: Exposure to periods of musical selections will result in greater activation of the sympathetic nervous system than exposure to identical durations of silence.

If H1a is supported, a logical subsequent is that as tempo of music itself increases-that is, as auditory structural onsets of beats increase in frequency - the activation of the sympathetic nervous system should also increase. Therefore:

H1b: There will be a main effect of Tempo on sympathetic nervous system activation as measured by SCRs.

Furthermore, prompted by previous research employing self-reported measures of arousal (Burns et al., 1999; Kellaris \& Kent, 1993) it is also hypothesized that genre will moderate the effects of tempo on arousal.

H1c: There will be significant effects of music genre on activation of the sympathetic nervous system as tempo increases.

If the onset of musical beats act as an auditory structural feature, then increasing their frequency will lead to comparatively greater levels of arousal. However, accounting for the dynamic nature of music processing, this increase in arousal will likely require time to fully manifest itself physiologically. Coupled with the expected decrease in arousal as experimental participants become accustomed to the testing session, the following hypothesis is made: 
H2a: Over the course of musical selections, participants will exhibit less deceleration in skin conductance levels while listening to fast-tempo music compared to slow-tempo music.

It is again expected that musical genre will impact this effect over time:

H2b: There will be a Tempo $\times$ Genre $\times$ Time interaction on skin conductance levels over the course of the musical selections.

\section{EXPERIMENT 1}

\section{Method}

Design. In order to address these hypotheses, a $3($ Tempo $) \times 2($ Genre $) \times$ 6 (Order of Presentation) mixed-measures experiment was designed and conducted. Music Tempo (fast, slow, none/silence) and Genre (rock, classical) were the two within-subject factors. The between-subject factor was Order of Presentation, of which there were six to which participants were randomly assigned.

Participants. Twenty-five university students took part in exchange for course credit in graduate or undergraduate courses. All gave informed consent prior to participating and were advised that they could terminate their participation at any time without penalty. No participants ended their session prematurely. Skin conductance data were lost from seven participants due to equipment malfunction.

Stimuli. Six auditory clips represented complete crosses of the Tempo and Genre factors: slow classical, fast classical, slow rock, fast rock, and two silence segments. Music was chosen according to beats per minute (bpm) timed by an electronic metronome. ${ }^{1}$ Clips were created by editing each song to create a natural-sounding selection devoid of lyrics and featuring a convincing beginning and ending. The fast-paced rock clip featured The Cult's "She Sells Sanctuary," which was approximately 50 seconds in duration with a steady tempo of $136 \mathrm{bpm}$. The 55-second fast-paced (139 bpm) classical stimulus was taken from Franz Liszt's "Hungarian Rhapsody No. 2 in C\# Minor." The 53-second slow-paced (76 bpm) rock stimulus was taken from "Trust" by The Cure. The 48-second slow-paced ( $74 \mathrm{bpm}$ ) classical selection was taken from the beginning of Antonin Dvořák's "Largo" from "Symphony No. 9 in E Minor." A discography is provided in Appendix 1.

These auditory selections were systematically placed into six unique orders on VHS videotapes. Each auditory selection was followed immediately

\footnotetext{
${ }^{1}$ Although musicology/music theory might suggest the use of either the time signature or suggested beats per measure of the score, the beats per minute measure was chosen to better operationalize the concept of structural feature onset of interest in this study.
} 
by excerpts from popular movies which lasted between 101 and 114 seconds. The six movie clips varied according to genre and were also systematically ordered to ensure that no musical selection appeared exclusively adjacent to a single movie excerpt. The presence of the movie clips served two purposes. One was to test a series of hypotheses not reported in this article. More relevant to the current predictions, however, was the desire to design the stimuli presentation to increase the ecological validity, bringing it in line with the interest in applying findings to the question of whether music tempo can drive autonomic arousal levels during a programming/station break/programming sequence.

Procedure. Individual participants were recruited to complete solo research sessions. Before the participant arrived at the research lab, safety checks were made on all electronic equipment, and all materials and equipment were prepared. Upon arriving at the pre-designated time, the participant was greeted and shown to a comfortable living room, with a cushioned chair facing a 27 -inch television set and videotape player. Behind the participant was a one-way window through which the experimenter could observe the stimulus presentation from a separate room, which also housed the psychophysiological data collection equipment. The participant only saw the mirrored side of the window and never observed the equipment or the experimenter once the procedure began.

The participant was invited to sit in the chair and was familiarized with the procedure and physiological electrodes before being given an informed consent form to sign and return. Once the participant had provided consent, any jewelry was removed as a safety precaution and electrodes were attached to the participant's nondominant hand. The participant had a few moments to become accustomed to the presence of the electrodes while the experimenter entered the adjacent room to calibrate the physiological equipment. After the calibration was complete, the experimenter returned to once again describe the procedures and turn on the television for the participant. Editing and playback equipment had been pre-calibrated such that all stimuli were presented at the same decibel level to control for loudness.

A single segment consisted of a brief musical selection or silence followed immediately by a short film clip. The TV screen was black during the music/silence portion of each segment. The experimenter paused both the videotape and the physiological data collection after each segment ended, allowing the participant to fill out evaluations of the film clip. After the participant had completed the questionnaire, their physiology was allowed to settle to stable baseline levels and the experimenter resumed stimuli presentation and data collection. This procedure was repeated for a total of six segments. Immediately thereafter, electrodes were removed from the participant who then filled out memory measures for the film clips. Afterwards, the participant was debriefed, thanked, and dismissed. 
Dependent variables. For this experiment, arousal was conceptualized as the activation of the sympathetic nervous system in response to environmental stimuli. Operationally, physiological arousal was defined using two quantifications of skin conductance: the skin conductance response (SCR) and skin conductance level (SCL). An SCR is a rapid rise in skin conductance occurring over the course of 1-3 seconds (Andreassi, 1995; Dawson, Schell, \& Fillion, 2000). SCL, however, is the actual tracking of the momentto-moment amount of conductivity occurring across electrodes placed on an experimental participant's palm. It is often operationalized by comparing a participant's conductivity level at any one second during a stimulus message to the second immediately preceding the onset of the message. Known as change scores, this comparison over time effectively identifies the effects of the stimulus alone because it, in essence, factors out any physiological arousal occurring as a result of the participant's state prior to stimulus onset (Dawson et al., 2000).

The measurements of skin conductance response and skin conductance level are related, of course. Lykken and Venables (1971) likened SCRs and the overall SCL to the waves on an ocean being responsible for the overall tidal drifts. They are both accepted as indications of the activation of the autonomic nervous system (Hopkins \& Fletcher, 1994) and have been used as operational definitions in a variety of media-related experiments (Bolls et al., 2001; Detenber, Simmons, \& Bennet, 1998; Potter et al., 2006).

Apparatus. The experiment was controlled by a Compaq Proline A 486 computer, with a LabMaster A/D-D/A board installed. The music/film clip stimuli were recorded on standard VHS videotape and played for the participants using a 4-head Panasonic VCR. The audio signal was delivered by a set of 4-inch Altec Lansing computer speakers placed on a table adjacent to the TV screen approximately 5 feet from the participant.

Skin conductance data were collected using a Coulbourn S71-22 skin conductance coupler. This module passes $.5 \mathrm{v}$ constant measurement voltage and compares conductivity levels across two standard AG/AGCL electrodes placed on the participant's nondominant hand. Each electrode was filled with nonconducting gel to improve adherence to the palm's surface without artificially escalating skin conductance levels. Prior to attaching the electrodes to the participant, a researcher wiped the skin with distilled water to ensure comparatively similar hydration levels across participants.

Data Reduction. Data were sampled at $20 \mathrm{~Hz}$ using the data collection program VPM-Version 11.0 (Cook, 1999). Each participant's skin conductance level was then computed, using VPMAnlog—version 6.5 (Cook, 1999), for each second during the music presentation along with the second immediately preceding the music onset.

SCRs were defined as a rise of at least 1 MicroSiemen over the course of 1-3 seconds during the music/silence presentation. SCR frequency was tallied manually during offline data reduction. 
For the SCL analysis, change scores were calculated for the first $40 \mathrm{sec}$ onds of each music segment and for the 40 seconds of both silence conditions. These change scores were then averaged over 5-second segments, resulting in a total of 8 data points for each music/silence stimulus.

All data were entered into the statistical program SPSS (Version 13.0 for Windows) for analysis.

\section{Results}

The theoretical basis for this study was that the recurring onset of musical beats could be conceptualized as auditory structural features. As such, it was expected that their occurrence would lead to physiological arousal in listeners. The first hypothesis stated that the very presence of music would result in greater sympathetic nervous system activation compared to silence. This hypothesis was tested using skin conductance response frequency, submitting these measures to a 3 (Genre) $\times 2$ (Tempo) repeated measures MANOVA. Results show a main effect for genre in SCR frequency $(F(2,34)=10.571$, $p<.001, \varepsilon^{2}=.3471$ ) which can be seen in Figure 1. Multiple comparisons with the Bonferroni adjustment show that subjects had significantly $(p<.05)$ more SCRs during both rock and classical clips than during periods of silence.

It was also predicted that increasing the tempo of the music would result in greater SCR occurrence. Removing the silence level from the Genre factor for this statistical test resulted in a series of 2 (Genre) $\times 2$ (Tempo) MANOVAs which returned no main effects (all $F$-values $<1$ ). However, it

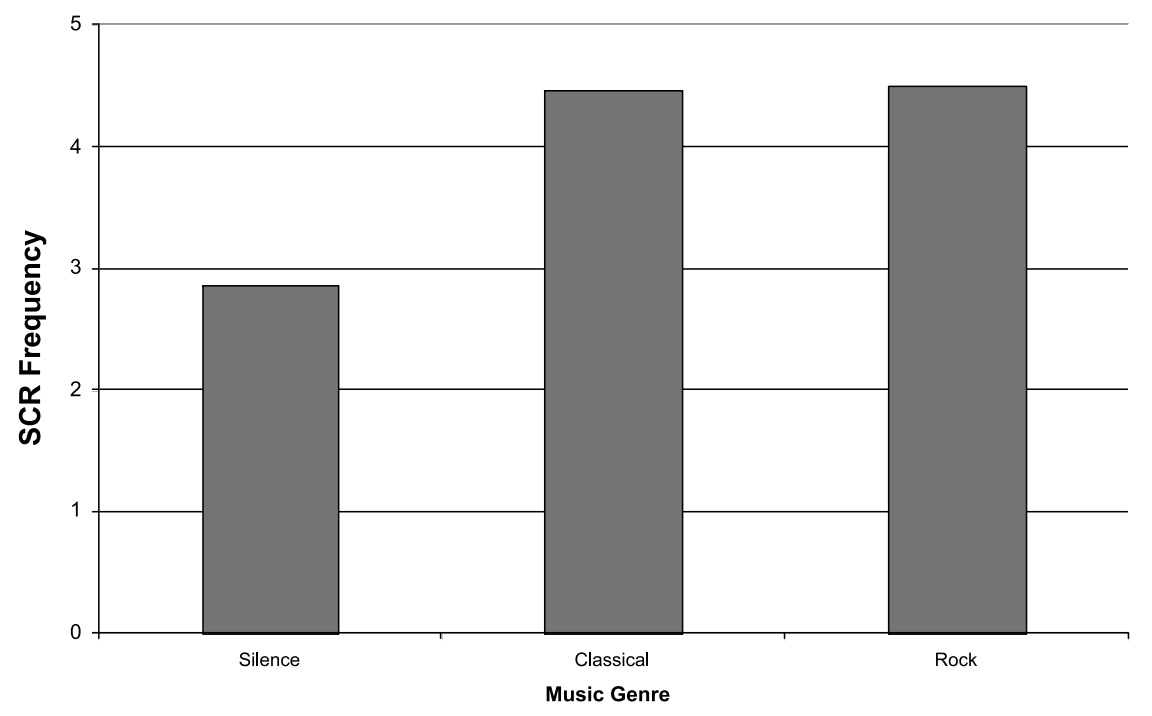

FIGURE 1 Skin Conductance Response (SCR) frequency main effects for classical music clips, rock music clips and silence across the listening period in Experiment 1. 
was also hypothesized that Tempo and Genre would significantly interact. This hypothesis was supported $\left(F(1,17)=5.550, p=.031, \varepsilon^{2}=.2018\right)$. As can be seen in Figure 2, the significant interaction is the reason behind the lack of a significant main Tempo effect. Increases in tempo resulted in significantly more SCRs in the classical music clips, whereas the opposite result was obtained for the rock music genre.

If the onset of musical beats serves as auditory structural onsets, it was predicted that introducing the factor of time would help to capture the dynamic nature of this process. Therefore, Hypothesis 2a stated that over the course of the musical selections participants will exhibit less deceleration in skin conductance levels while listening to fast-tempo than slow-tempo music. To test this hypothesis the aggregated SCL change score segments were submitted to a $2($ Genre $) \times 2($ Tempo $) \times 9$ (Time) repeated measures MANOVA which resulted in a significant main effect for Tempo $(F(1,16)=9.040, p=$ $\left..008, \varepsilon^{2}=.4009\right)$. As can be seen in Figure 3, fast-tempo music did, as predicted, generate greater activation of the sympathetic nervous system than slow-tempo music. Furthermore, even though both tempo levels initially rose above baseline levels, slow-tempo music decelerated below baseline by the second segment whereas SCL during fast-tempo music did not dip below baseline until the fourth segment. Although the Tempo $\times$ Time interaction was not statistically significant $(F(8,128)=1.437, p=.187)$, beginning at

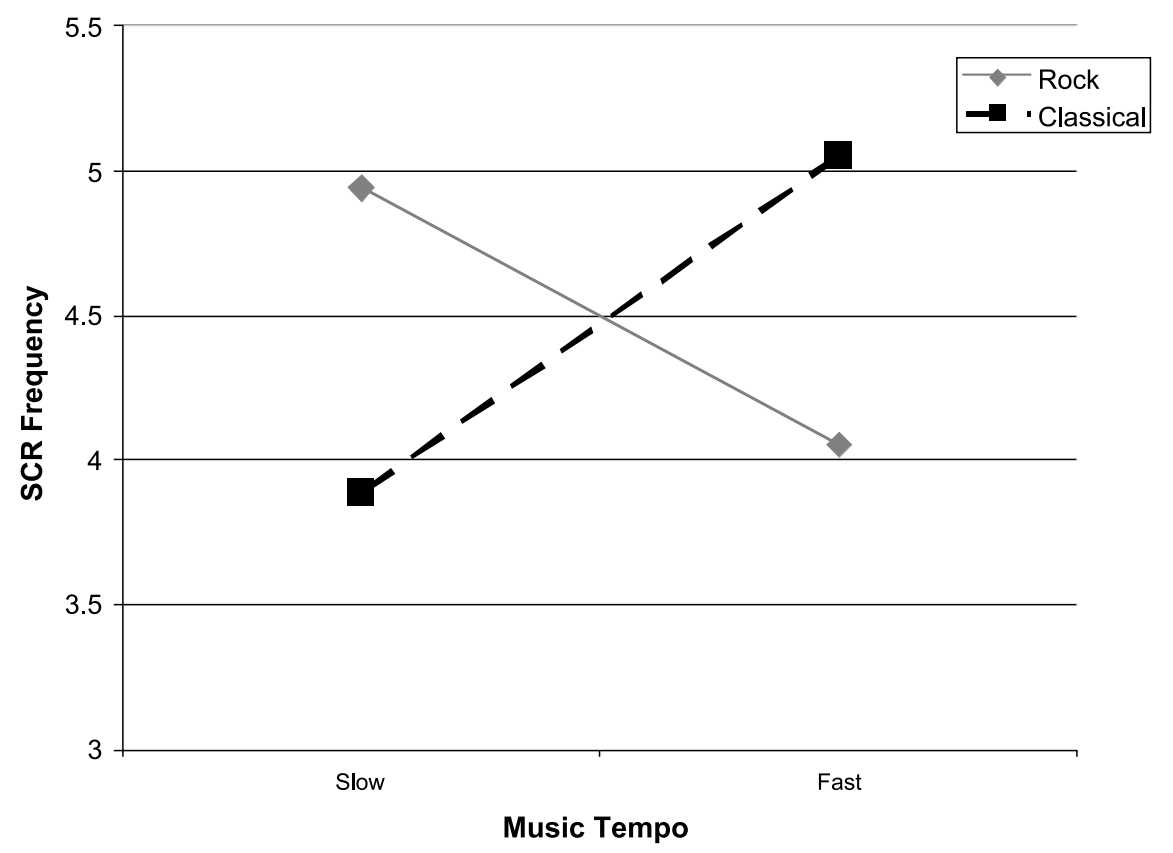

FIGURE 2 Skin Conductance Response (SCR) frequency interaction effect for music genre (classical, rock) and music tempo (slow, fast) across the listening period in Experiment 1. 


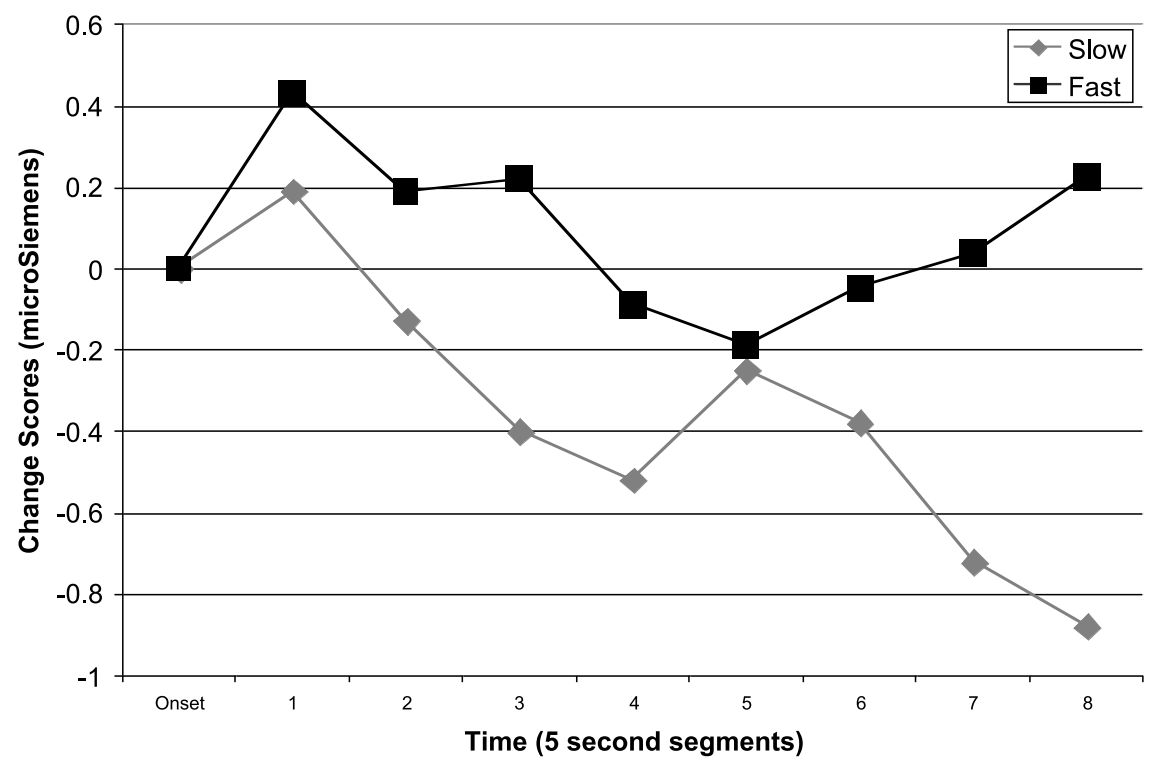

FIGURE 3 Skin Conductance Level (SCL) change score main effect for music tempo (slow, fast) over the listening period in Experiment 1, measured in 5-sec increments.

time segment 5 (about 25 seconds into the music clip), the two tempo conditions sharply diverge in the predicted direction. Hypothesis $2 \mathrm{~b}$, predicting that this effect over time would be significantly impacted by Genre, was not supported $(F$-values $<1)$.

\section{Discussion}

This first experiment used psychophysiological measures to confirm that the presence of any music, whether slow- or fast-paced, increases arousal in the sympathetic nervous system. With this basic effects test completed, the next task was to assess whether tempo, beyond the influences of other musical features, increased arousal; keeping in mind that the music's texture (genre) would likely moderate any tempo effects on skin conductance over time. When the dynamic nature of the music processing task was taken into account by using SCL as the dependent measure, music with a faster beat sustained greater sympathetic activation than did music with a slower beat, as predicted. This main effect was not found when evaluating the entire listening period aggregated across time using a frequency count of all spontaneous SCRs. Instead, the significant interaction with genre-where tempo increases led to significantly more SCRs in during classical music processing but significantly less during rock music processing — eliminated the predicted main effect. 
One possible explanation for why tempo increases activated the sympathetic system for classical music but not for rock music is the overall familiarity of the rock genre itself among the experimental participants, coupled with the fact that upbeat rock could be considered more exemplary of the particular genre than slow-tempo rock. In other words, it is possible that the fast-paced rock was viewed as predictable and somewhat mundane whereas classical music is more expected to be slow in tempo. As a result, it is possible that not only was the overall arousal level of participants dampened due to the mundane nature of the rock genre, but that they more quickly adjusted to the rapid onset of individual notes in an expected genre-andtempo pairing.

\section{EXPERIMENT 2}

\section{Method}

Overview. In light of the results of the first experiment, it was not necessary to again compare music with silence. Instead, the choice was made to further explore how genre might moderate tempo both over the aggregated listening period and dynamically over time. Considering that the genre interaction in Experiment 1 may have occurred because of the combination of increased tempo and greater familiarity with rock music, Experiment 2 sought to replicate this finding, as well as expand upon the expected genre familiarity effect by incorporating another genre-swing - into the design. At the time these data were collected, fast-paced swing music was making a comeback on college dance floors and on radio airwaves (Judge, 1999; Parish, 1999). It was therefore expected that sympathetic activation to swing would more closely resemble activation during rock music than during classical music. Therefore, different musical selections were chosen across classical, rock, and swing genres and a similar experimental design was used to test the following hypotheses:

H1: There will be a Genre $\times$ Tempo interaction on sympathetic nervous system activation such that tempo increases will result in greater SCR activity during classical music but not the more familiar genres of rock and swing.

H2: Over the course of the musical selections, participants will exhibit less deceleration in SCL while listening to fast-tempo music than slow-tempo music.

Design. In order to address these hypotheses, a 2 (Tempo) $\times 3$ (Genre) $\times 6$ (Order of Presentation) mixed-measures experiment was designed and 
executed. Music Tempo (fast, slow) and Genre (rock, classical, swing) were the two within-subject factors. The between-subject factor was Order of Presentation, of which there were six to which participants were randomly assigned. For the most part, Experiment 2 used the same dependent variables, data reduction, and general protocol as Experiment 1. Differences are noted below.

Participants. Twenty-five undergraduates agreed to participate. Skin conductance data from four of them were unusable. Participants were solicited and compensated in the same manner as in the first experiment. No single participant completed both protocols.

Procedure. The procedure was the same as in the first experiment. However, rather than hearing two segments of silence over the course of the protocol, participants heard six music clips as described below.

Stimuli. Music clips were selected, edited and ordered in the same manner as in Experiment 1. Rather than silence, however, samples of swing music were included as a third level of the genre factor. The fast-paced (138 bpm) rock clip was taken from "Who's There?" by Smash Mouth. The fast-paced (140 bpm) classical clip featured the finale of the "William Tell Overture" by Rossini. The fast-paced (bpm 136) swing clip was taken from "Got My Own Thing Now" by the Squirrel Nut Zippers.

The slow-paced (78 bpm) rock clip was taken from Lightning Seeds' rendition of "You Showed Me." The slow-paced (75 bpm) classical clip featured Pachelbel's "Canon in D." The slow-paced $(74 \mathrm{bpm})$ swing clip featured "Meant to Be" by The Squirrel Nut Zippers. (See Appendix 1 for discography.)

\section{Results}

Data for SCR frequency are shown in Figure 4. These values were submitted to a 3 (Genre) $\times 2$ (Tempo) repeated measures MANOVA. Although the figure for SCR frequency resembles that predicted, the only significant result was a main effect for Genre $\left(F(2,40)=6.947, p=.003, \varepsilon^{2}=.2207\right)$, with activation for classical greater regardless of tempo.

To address Hypothesis 2, that participants' SCLs would decelerate slower during fast-tempo music than during slow-tempo music, change scores were submitted to a 3 (Genre) $\times 2$ (Tempo) $\times 9$ (Time) repeated measures MANOVA, the results of which approached significance $(F(16,256)=1.502$, $\left.p=.099, \varepsilon^{2}=.0287\right)$. Inspection of Figure 5 shows no impact for tempo on the rock music excerpts over time. However, tempo has marked effects on the other two genres. Contrary to predictions, however, faster tempo led to increased sympathetic activation in the supposedly morefamiliar swing genre and decreased activation in the less-familiar classical genre. 


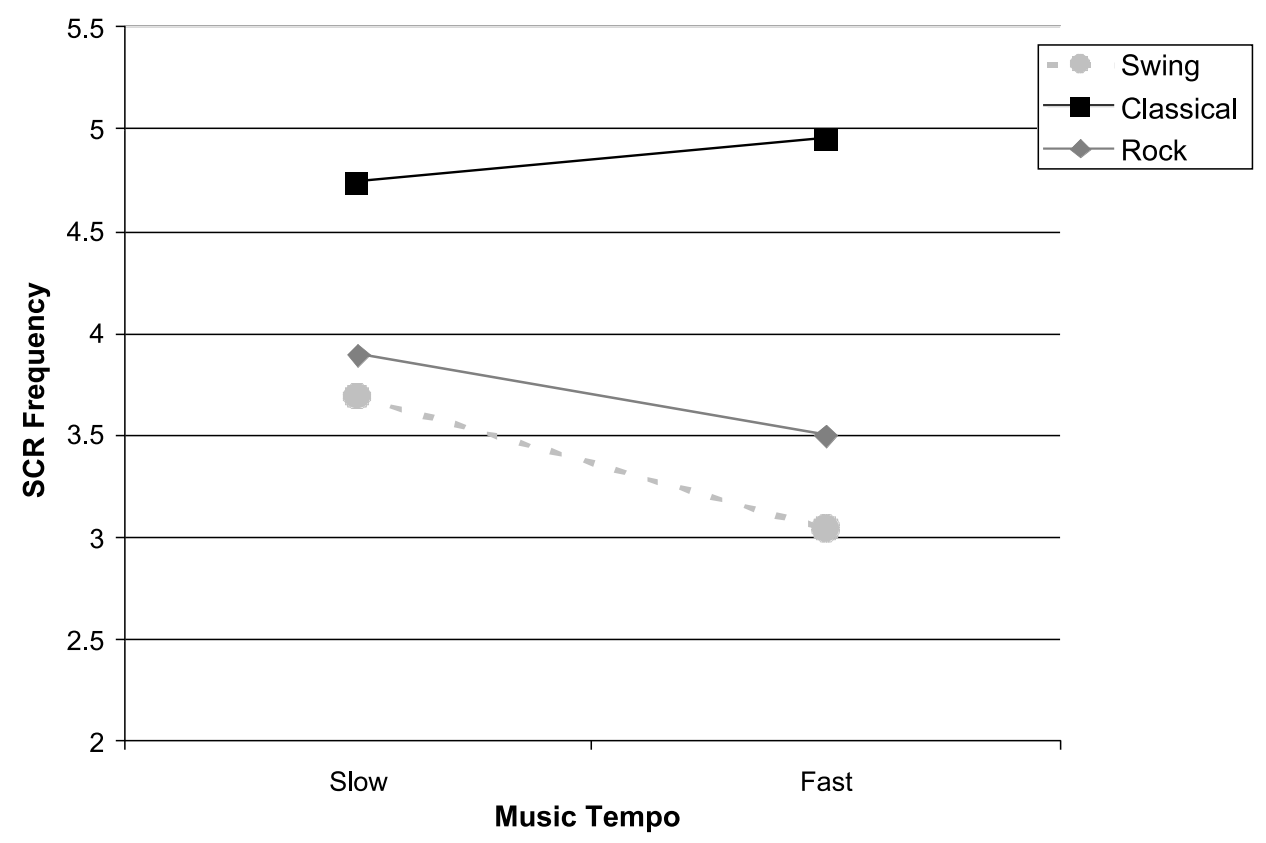

FIGURE 4 Skin Conductance Response (SCR) frequency interaction effect for music genre (swing, classical, rock) and music tempo (slow, fast) across the listening period in Experiment 2 .

\section{Discussion}

Experiment 1 showed that increasing the tempo of classical music clips led to greater skin conductance response frequency in the college-aged participants. Increasing the tempo of rock music, on the other hand, led to a precipitous decrease in such activity. A possible explanation offered post-hoc was that such an interaction may have occurred because of the combination of increased tempo and lack of familiarity with the classical genre, whereas rock music was familiar and furthermore fast-tempo was expected in the genre by participants.

Given this, Experiment 2 forewent the comparison of music to silence and instead focused on the potential tempo effects for music selections representing three different genres. It was expected that fast-tempo classical music would yield increased arousal compared to slow-tempo classical music, whereas rock and swing would demonstrate the opposite impact of tempo increase. Although not significant, the pattern of mean SCR frequencies was in the predicted direction. Interestingly, classical music did activate the sympathetic system to a significantly greater extent than either the rock or swing genres regardless of tempo, in partial support of the familiarity argument presented following Experiment 1. 

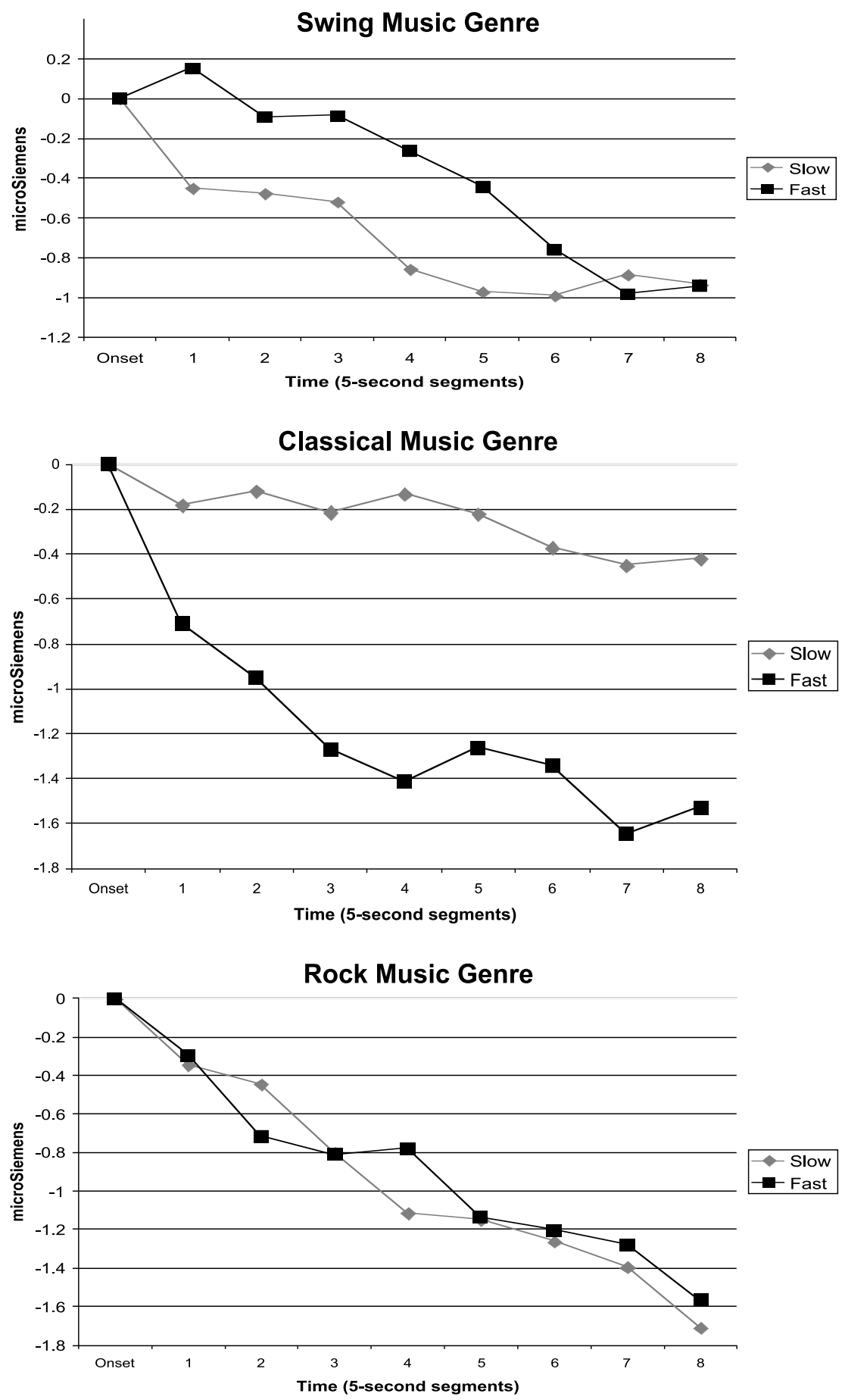

FIGURE 5 Skin Conductance Level (SCL) change score interaction effect for music genre (swing, classical, rock) and music tempo (slow, fast) over the listening period in Experiment 2, measured in 5-sec increments. 
Significant results for the Tempo $\times$ Genre $\times$ Time interaction were not expected, as they were not found in Experiment 1. Nevertheless, here rock music showed the hypothesized lack of divergence across the two levels of the Tempo factor, whereas marked effects of tempo were found among the swing and classical music. However, the direction of the effects across these two genres was contrary to prediction. The presumably more-familiar genre of swing music had greater sympathetic activation in response to fast tempo (even having change scores initially rising above baseline levels) compared to slow, whereas the presumably less-familiar classical selections showed greater activation for slow tempo compared to fast.

Thus, Experiment 2 continued to demonstrate that tempo is a significant variable in the activation of the sympathetic nervous system and one which interacts with musical genre. However, the familiarity assumptions surrounding rock and classical music suggested by interpreting the results from Experiment 1 (and by extension a similar assumption regarding swing music) proved to be unsuccessful in accurately predicting the directions of that interaction.

\section{GENERAL DISCUSSION}

This pair of experiments attempted to test three broad hypotheses. First, it was proposed that the onset of musical notes could be conceptualized as auditory structural features that activate the sympathetic branch of the autonomic nervous system as indexed by skin conductance measures. Second, it was proposed that increasing the average rate at which such notes occuressentially increasing the tempo of the musical clip-increase a listener's physiological arousal. Finally, in accordance with previous research using self-report measures, these first two findings should be moderated by the particular genre of music to which participants were exposed.

In general, all three of these hypotheses were confirmed. Results suggest that it is indeed feasible to conceptualize musical beats as auditory structural features capable of activating sympathetic arousal. As seen in Figure 1, clips of both rock music and classical music elicited SCRs more frequently than during equal durations of silence. Furthermore, increasing the tempo of music increased arousal responses. This is clearly seen in Figure 3, wherein SCLs were significantly greater for fast tempo music compared to slow, and there was substantially greater divergence in sympathetic activation as the music continued over time. Similarly, the expected tempo effect is seen in SCR frequencies for classical music (Figures $2 \& 4$ ) as well as in SCL change scores for swing music (Figure 5). The combination of these genre-specific effects, with occasions where increases in tempo for certain genres resulted in decreases in autonomic arousal, lend support to the third general hypothesis: genre matters when it comes to the impact of tempo on arousal. 
What remains an open question for future research is exactly how musical genre moderates the impact of tempo. A fourth prediction emerged following Experiment 1, where an interaction showed tempo-driven increases in arousal for classical music but decreases in arousal for rock. We considered that perhaps it was the familiarity and typicality of fast tempos in the rock genre, combined with the typicality of slow tempos in the less familiar classical genre, which led to this result. Past research using self-selected musical selections either as the sole stimuli or in conjunction with other experimenter-chosen selections also alludes to the notion of familiarity as key (e.g., Juslin \& Sloboda, 2001). However, this prediction was not supported in Experiment 2, where the deceleration effect for rock music itself failed to replicate and SCL results showed that, this time, increasing tempo for classical music resulted in lower sympathetic activation but higher activation in swing music.

In hindsight, we wondered if these unexpected results were a flaw in our procedure for Experiment 2, namely that merely presuming relative familiarity of the three genres rather than measuring it in the participants was in error. The initial presumptions were based on an understanding of music popularity and radio listening habits of the particular age group involved. For example, according to Arbitron's (2006) fall 2006 ratings figures, people between the ages of 18 and 24 listened most to the following genres: Contemporary Hit Radio (24.9 share), Spanish (15.8 share), Urban (14.3 share), Adult Contemporary (10.7 share), and Rock (8.8 share). Classical stations were among the least listened to in this age group, earning 0.1 share of that audience for the quarter. Nevertheless, we attempted to confirm our assumptions by collecting data post-hoc from a third group of participants who rated each of the ten musical clips used in these experiments (along with about 30 other song excerpts of similar duration) on a variety of variables including familiarity. These data confirmed our genre familiarity assumptions made about the stimuli used in both experiments: rock music was more familiar than classical, with swing music from Experiment 2 rated in between.

Given this, we would argue that our data suggest that familiarity and typicality of tempo in particular music types do not moderate the tempo effect via the genre variable. Unfortunately (or fortunately?), this is one area where our results do not provide answers, but rather raise more questions for future investigations. What are the other variables that, depending on tempo, sometimes raise sympathetic arousal and sometimes decrease it?

In addition to isolating which aspects of musical genre impact the effects of tempo, future research should also attempt to directly test the excitation transfer ability of music (see Zillmann, 1971 for excitation transfer theory). In one study, exciting film clips were found to have an excitation-transfer effect on music, whereby increasingly arousing film clips led to greater liking of a rock song heard a few minutes after viewing the clip (Cantor \& Zillmann, 1973). Other studies have shown the ability for physiologically- 
arousing video segments to intensify emotional responses to mediated (Zillmann, Mody, \& Cantor, 1974) or nonmediated stimuli (Cantor, Zillmann, \& Einsiedel, 1978). In addition, increased arousal from physical exercise has resulted in higher ratings of arousal and enjoyment of later media content (Cantor, Zillmann, \& Bryant, 1975). Although our results provide cursory insight into the type of music that would be most effective, we are aware of no research directly testing how music can optimally stimulate an audience, transferring arousal to subsequent entertainment or persuasive content.

We suggest that future experimental designs consider multiple examples of music across levels of genre and tempo. Furthermore, future studies should consider using multiple age groups as participants, as music preferences can vary widely both within and across age ranges. Although we did not consider musical training of our participants, influenced at the design-stage by studies (e.g., Rickard, 2004) that found no appreciable effects of this variable, we would recommend this is still a factor that should be considered in future studies, as it might speak to genre familiarity and liking. Future studies might also consider using other measures of physiological arousal in addition to skin conductance. As Ravaja (2004) explains, the body manifests different physiological patterns of responses when experiencing different emotions. The substantial literature on differential impact of music on discrete emotions suggests that triangulating physiological measures of arousal, rather than relying on a single index, would be wise.

Thinking broadly, the most salient lesson learned from these experiments is how to interpret music within an established communication research stream. Specifically, we attempted to determine if musical clips, such as those used in radio or television advertisements, could be interpreted using a structural features conceptualization previously applied to radio and television messages. In this approach, the number of cuts within a video scene has provided enough environmental variance to elicit orienting responses and subsequent changes in physiological arousal (e.g., Lang et al., 1999; Lang, Zhou, Schwartz, Bolls, \& Potter, 2000). Likewise, increasing the frequency of onset of structural features in radio advertisements has delivered similar effects (Potter \& Callison, 2000; Potter \& Choi, 2006; Potter et al., 2002). In these examples, the actual content of the video shot or content of the radio dialogue was secondary to the "rhythm" of the structural onset. Drawing from this tradition, we investigated whether treating the onset of musical beats as structural features would yield similar results, in that increasing the onset, or frequency, of beats over time (increasing tempo) should increase arousal, regardless of the "content" of the music.

What we discovered was that, when it comes to music, the "content" matters. The effect of notes-as-structure markedly varied according to the genre of music. Perhaps it is that not enough of a change happens with the 
onset of a single beat to make an appreciable difference in arousal. One could argue that successive steady beats become monotonous, such that individuals quickly habituate to their onset. Thus, the beats fade into the background, and the texture and melody become the noticeable features. To summarize, the musical texture absolutely must be taken into account, thinking of tempo instead as enhancing the texture, rather than vice versa.

This might be somewhat distressing for message designers, who wish to enhance the effects of their messages with music obtained within the confines of their design environment. Given such constraints as music licensing and contracts, project timelines, or desires of clients and employers to use certain popular bands or songs, for example, it might be difficult to select the most effective musical accompaniment if one must evaluate features besides how fast or slow the song is. Hopefully, additional research into the commercial use of different templates of music can help reduce this pool of possibilities and guide production professionals and students toward more consistent musical underscoring choices.

In 1972, famed pianist and conductor André Previn said "There are a million things in music I know nothing about. I just want to narrow down that figure." Though the findings are not entirely consistent, this investigation succeeds in providing key lessons that can be translated into application by message designers. Clearly, more research is needed into the various features and dynamics of music to evaluate their role in shaping the listening experience. However, perhaps as our understanding of music-induced arousal increases, our ability to predict music effects will improve, leading to a more successful and strategic use of this potentially powerful communication form.

\section{REFERENCES}

Alten, S. R. (2005). Audio in media. Belmont, CA: Wadsworth Publishing Company. Andreassi, J. L. (1995). Psychophysiology: Human behavior \& physiological response. Hillsdale, NJ, Lawrence Erlbaum Associates.

Arbitron. (2006). American listening radio trends: Format trends report. Retrieved February 09, 2007 from http://wargod.arbitron.com/scripts/ndb/fmttrends2.asp

Arnett, J. (1991). Heavy metal music and reckless behavior among adolescents. Journal of Youth and Adolescence, 20, 573-592.

Arnett, J. (1992). The soundtrack of recklessness: Musical preference and reckless behavior among adolescents. Journal of Adolescent Research, 7, 313-331.

Bartlett, D. (1996). Neuromusical research: A review of the literature. In D. A. Hodges (Ed.), Handbook of music psychology (pp. 343-385). San Antonio, TX: IMR Press.

Bever, T. G. (1988). A cognitive theory of emotion and aesthetics in music. Psychomusicology, 7, 165-175.

Bigand, E., Filipic, S., \& Lalitte, P. (2005). The time course of emotional responses to music. Annals of the New York Academy of Sciences, 1060, 429-437. 
Bolls, P. D., Lang, A., \& Potter, R. F. (2001). The effects of message valence and listener arousal on attention, memory, and facial muscular responses to radio advertisements. Communication Research, 28, 627-651.

Bradley, M. M. (1994). Emotional memory: A dimensional analysis. In S. Van Goozen, N. E. Van de Poll, \& J. A. Sergeant (Eds.), Emotions: Essays on emotion theory (pp. 97-134). Hillsdale, NJ: Lawrence Erlbaum Associates.

Burns, J., Labbe, E., Williams, K., \& McCall, J. (1999). Perceived and physiological indicators of relaxation: As different as Mozart and Alice in Chains. Applied Psychophysiology and Biofeedback, 24, 197-202.

Cantor, J. R., \& Zillmann, D. (1973). The effect of affective state and emotional arousal on music appreciation. Journal of General Psychology, 89, 97-108.

Cantor, J. R., Zillmann, D., \& Bryant, J. (1975). Enhancement of experienced sexual arousal in response to erotic stimuli through misattribution of unrelated residual excitation. Journal of Personality and Social Psychology, 32, 69-75.

Cantor, J. R., Zillmann, D., \& Einsiedel, E. F. (1978). Female responses to provocation after exposure to aggressive and erotic films. Communication Research, 5, 395412.

Cook, E. W. I. (1999). VPMANLOG. Birmingham, AL.

Davis, W. B., \& Thaut, M. H. (1989). The influence of preferred relaxing music on measures of state anxiety, relaxation, and physiological responses. Journal of Music Therapy, 26, 168-187.

Davis-Rollans, C., \& Cunningham, S. G. (1987). Physiologic responses of coronary care patients to selected music. Heart \& Lung, 16, 370-378.

Dawson, M. E., Schell, A. M., \& Filion, D. L. (2000). The electrodermal system. In J. T. Cacioppo \& L. G. Tassinary (Eds.), Handbook of psychophysiology (2nd ed., pp. 200-223). New York: Cambridge University Press.

Dehyle, D. (1998). From break dancing to heavy metal: Navajo youth, resistance, and identity. Youth and Society, 30, 3-31.

Detenber, B. H., Simons, R. F., \& Bennet, G. G. (1998). Roll 'em!: The effects of picture motion on emotional responses. Journal of Broadcasting and Electronic Media 42, 113-127.

Dillman Carpentier, F., Knobloch, S., \& Zillmann, D. (2003). Rock, rap, and rebellion: Comparisons of traits predicting selective exposure to defiant music. Personality and Individual Differences, 35, 1643-1655.

Frith, S. (1981). Sound effects. New York: Pantheon Books.

Gabrielsson, A., \& Lindström, E. (2001). The influence of musical structure and emotional expression. In P. Juslin \& J. A. Sloboda (Eds.), Music and emotion: Theory and research (pp. 223-248). Oxford: Oxford University Press.

Gaver, W. W., \& Mandler, G. (1987). Play it again, Sam: On liking music. Cognition and Emotion, 1, 259-282.

Hansen, C. H., \& Hansen, R. D. (2000). Music and music videos. In D. Zillmann \& P. Vorderer (Eds.), Media entertainment: The psychology of its appeal (pp. 175196). Mahwah, NJ: Lawrence Erlbaum Associates.

Holbrook, M. B., \& Anand, P. (1990). Effects of tempo and situational arousal on the listener's perceptual and affective responses to music. Psychology of Music, $18,150-162$. 
Hopkins, R., \& Fletcher, J. E. (1994). Electrodermal measurement: Particularly effective for forecasting message influence on sales appeal. In A. Lang (Ed.), Measuring psychological responses to media (pp. 113-132). Hillsdale, NJ: Lawrence Erlbaum Associates.

Husain, G., Thompson, W. F., \& Schellenberg, E. G. (2002). Effects of musical tempo and mode on arousal, mood, and spatial abilities. Music Perception, 20, 151171.

Judge, M. G. (1999, Aug/Sept). Back to the future. First Things, 95, 14-16.

Juslin, P. N., \& Laukka, P. (2003). Communication of emotions in vocal expression and music: Different channels, same code? Psychological Bulletin, 129, 770814.

Juslin, P., \& Sloboda, J. A. (2001). Music and emotion: Theory and research. Oxford, UK: Oxford University Press.

Kellaris, J. J., \& Kent, R. J. (1993). An exploratory investigation of responses elicited by music varying in tempo, tonality, and texture. Journal of Consumer Psychology, 2, 381-401.

Kendall, R. A., \& Carterette, E. C. (1990). The communication of musical expression. Music Perception, 8, 129-164.

Krumhansl, C. L. (1997). An exploratory study of musical emotions and psychophysiology. Canadian Journal of Experimental Psychology, 51, 336-352.

Lang, A., Bolls, P., Potter, R. F., \& Kawahara, K. (1999). The effects of production pacing and arousing content on the information processing of television messages. Journal of Broadcasting and Electronic Media, 43, 451-475.

Lang, A., Zhou, S., Schwartz, N., Bolls, P. D., \& Potter, R. F. (2000). The effects of edits on arousal, attention, and memory for television messages. Journal of Broadcasting \& Electronic Media, 44, 94-109.

Leman, M. (2003, Fall). Foundations of musicology as content processing science. Journal of Music and Meaning, 1, section 3.2. Retrieved August 15, 2007 from http://www.musicandmeaning.net/issues/showArticle.php?artID $=1.3$

Lundin, R. W. (1985). An objective psychology of music, 3rd ed. Malabar, FL: Robert E. Krieger Company.

Lykken, D. T., \& Venables, P. H. (1971). Direct measurement of skin conductance: A proposal for standardization. Psychophysiology 13, 554-562.

Manuel, P. (1991, Winter). Latin music in the United States: Salsa and the mass media. Journal of Communication, 41, 104-116.

McLeod, K. (1999). Authenticity within hip-hop and other cultures threatened with assimilation. Journal of Communication, 49, 134-150.

Nabi, R. L. (1999). A cognitive-functional model for the effects of discrete negative emotions on information processing, attitude change, and recall. Communication Theory, 9, 292-320.

Nabi, R. L. (2003). The framing effects of emotion: Can discrete emotions influence information recall and policy preference? Communication Research, 30, 224-247.

Newhagen, J. E. (1998). TV news images that induce anger, fear, and disgust: Effects on approach-avoidance and memory. Journal of Broadcasting and Electronic Media, 42, 265-276.

Ortony, A., Clore, G. L., \& Collins, A. (1988). The cognitive structure of emotions. Cambridge, UK: Cambridge University Press. 
Osgood, C., Suci, G., \& Tannenbaum, P. (1957). The measurement of meaning. Urbana, IL: University of Illinois.

Parish, P. (1999). The Lindy Hop: A revival in full swing. Dance Magazine, 73, $50-52$.

Pelletier, C. L. (2004). The effect of music on decreasing arousal due to stress: A meta-analysis reference. Journal of Music Therapy, 41, 192-214.

Peretz, I. (2001). Listen to the brain: The biological perspective on musical emotions. In P. Juslin \& J. A. Sloboda (Eds.), Music and emotion: Theory and research (pp. 105-134). Oxford, UK: Oxford University Press.

Potter, R. F. (2000). The effects of voice changes on orienting and immediate cognitive overload in radio listeners. Media Psychology, 2, 147-178.

Potter, R. F. (2006). Made you listen: The effects of production effects on attention to short radio promotional announcements. Journal of Promotion Management, $12,35-48$.

Potter, R. F., \& Callison, C. (2000). Sounds exciting!: The effects of audio complexity on listeners' attitudes and memory for radio promotional announcements. Journal of Radio Studies, 7, 29-51.

Potter, R. F. \& Choi, J. (2006). The effects of auditory structural complexity on attitudes, attention, arousal \& memory. Media Psychology, 8, 395-419.

Potter, R. F., Choi, J., Yu, H.-S., Kim, J., \& Dillman Carpentier, F. (2002). Increased memory for structurally complex radio messages: Could arousal be the mechanism? Psychophysiology, 39 (S1), 67.

Potter, R. F., Lang, A., \& Bolls, P. D. (1998). Orienting to structural features in auditory media messages. Psychophysiology, 35, $\mathrm{S} 66$.

Potter, R. F, LaTour, M., Braun-LaTour, K., \& Reichert, T. (2006). Program context effects on an appeal to fear. Journal of Advertising, 35, 69-82.

Ravaja, N. (2004). Contributions of psychophysiology to media research: Review and recommendations. Media Psychology, 6, 193-235.

Reisenzein, R. (1994). Pleasure-arousal theory and the intensity of emotions. Journal of Personality and Social Psychology, 67, 525-539.

Rickard, N. S. (2004). Intense emotional responses to music: A test of the physiological arousal hypothesis. Psychology of Music, 32, 371-388.

Robb, S. L., Nichols, R. J., Rutan, R. L., Bishop, B. L., \& Parker, J. C. (1995). The effects of music assisted relaxation on preoperative anxiety. Journal of Music Therapy, 32, 2-21.

Russell, J. A. (1980). A circumplex model of affect. Journal of Personality and Social Psychology, 39, 1161-1178.

Scherer, K. R., \& Zentner, M. R. (2001). Emotional effects of music: Production rules. In P. N. Juslin \& J. A. Sloboda (Eds.), Music and emotion: Theory and research (pp. 361-392). New York: Oxford University Press.

Schubert, E. (2004). Modeling perceived emotion with continuous musical features. Music Perception, 21, 561-585.

Sellnow, D., \& Sellnow, T. (2001). The "illusion of life" rhetorical perspective: An integrated approach to the study of music as communication. Critical Studies in Media Communication, 18, 395-415.

Sloboda, J. A. (1991). Music structure and emotional response: Some empirical findings. Psychology of Music, 19, 110-120. 
Stewart, C., Smith, C., \& Denton, R. (1989). Persuasion and social movements, 2nd ed. Prospect Heights, IL: Waveland Press.

Standley, J. M. (1991). The role of music in pacification/stimulation of premature infants with low birthweights. Music Therapy Perspectives, 9, 19-25.

Strauser, J. M. (1997). The effects of music versus silence on measures of state anxiety, perceived relaxation, and physiological responses of patients receiving chiropractic interventions. Journal of Music Therapy, 34, 88-105.

Sundar, S. S., \& Kalyanaraman, S. (2004). Arousal, memory, and impression-formation effects of animation speed in web advertising. Journal of Advertising, 33, 7-17.

Tagg, P. (2002). Towards a definition of 'music.' Taken from provisional course text A short prehistory of popular music. Available at http://www.unigre.it/pug/cics/ CO2113/Tagg.pdf

Thayer, R. E. (1989). The biopsychology of mood and arousal. New York: Oxford University Press.

Wirth, W., \& Schramm, H. (2005). Media and emotions. Communication Research Trends 24(3), 1-22.

Yoon, K., Bolls, P., \& Lang, A. (1998). The effects of arousal on liking and believability of commercials. Journal of Marketing Communications, 4, 101-114.

Zajonc, R. B. (1980). Feeling and thinking: Preferences need no inferences. American Psychologists, 35, 151-175.

Zillmann, D. (1971). Excitation transfer in communication-mediated aggressive behavior. Journal of Experimental Social Psychology, 7, 419-434.

Zillmann, D., Mody, B., \& Cantor, J. R. (1974). Empathetic perception of emotional displays in films as a function of hedonic and excitatory state prior to exposure. Journal of Research in Personality, 8, 335-349.

\section{APPENDIX}

\section{Experiment 1 Discography}

Liszt, F. (1853). Hungarian rhapsody no. 2, C sharp minor. Norddeutsche Philharmonie. Robert Nagel. On Classical treasures: Classics in the movies [compact disc]. St. Laurent, Quebec, Canada: The Madacy Music Group Inc. (199-?).

Dvorak, A. (1893). Symphony no. 9 in E minor, Op. 95, 2nd mvt (largo). Philharmonia Orchestra. Carlo Maria Giulini. On Dvorak [compact disc]. USA: EMI Records Ltd. (1988).

The Cult. (1985). She sells sanctuary. On With Honors: Music From the motion picture soundtrack [compact disc]. USA: WEA/Warner Bros. (1994).

The Cure. (1992). Trust. On Wish [compact disc]. USA: Elektra.

\section{Experiment 2 Discography}

Rossini, G. (1829). William Tell-overture. New Philharmonic Orchestra London. Alfred Scholz. On Classical treasures: Classics in the movies [compact disc]. St. Laurent, Quebec, Canada: The Madacy Music Group Inc. (199-?). 
Pachelbel, J. (c. 1680). Canon and gigue for strings, D major. Camerata Academica Salzburg. Bernhard Paumgartner. On Classical treasures: Classics in the movies [compact disc]. St. Laurent, Quebec, Canada: The Madacy Music Group Inc. (199-?).

Smash Mouth. (1999). Who's there. On Astro lounge [compact disc]. USA: Interscope Records.

Lightning Seeds. (1997). You showed me [Originally recorded in 1968 by The Turtles]. On Dizzy heights [compact disc]. USA: Sony.

Squirrel Nut Zippers. (1996). Got my own thing now. On Hot [compact disc]. USA: Fontana Mammoth.

Squirrel Nut Zippers. (1996). Meant to be. On Hot [compact disc]. USA: Fontana Mammoth. 
Copyright of Media Psychology is the property of Lawrence Erlbaum Associates and its content may not be copied or emailed to multiple sites or posted to a listserv without the copyright holder's express written permission. However, users may print, download, or email articles for individual use. 